\title{
ENSAIOS GEOFÍSICOS NO ATERRO SANITÁRIO DE CUIABÁ-MT
}

\author{
Andreza Thiesen Laureano ${ }^{1}$ e Shozo Shiraiwa² \\ Recebido em 7 agosto, 2007 / Aceito em 19 março, 2008 \\ Received on August 7, 2007 / Accepted on March 19, 2008
}

\begin{abstract}
This work aims to study a possible contamination caused by the Cuiabá Landfill, Mato Grosso, Brazil, through electromagnetic inductive method and Ground Penetrating Radar survey. The first waste disposal cell and the leachate treatment lagoons had been never impermeabilized, being potential sources of subsoil contamination. The results suggest that the entire landfill was contaminating the subsoil, including the impermeabilized area.
\end{abstract}

Keywords: electromagnetic induction, GPR - Ground Penetrating Radar, waste, leachate, contamination plume.

RESUMO. Este trabalho mapeou a condutividade elétrica do subsolo e associou a provável contaminação causada pelo atual aterro sanitário de Cuiabá, MT, através do método eletromagnético indutivo e do Radar de Penetração no Solo (GPR). A primeira célula de disposição de lixo e as lagoas de tratamento de chorume nunca foram impermeabilizadas, sendo fontes potenciais de contaminação do subsolo. Os resultados sugerem que todo o aterro estava contaminando 0 subsolo, inclusive a área impermeabilizada.

Palavras-chave: indução eletromagnética, GPR - Radar de Penetração no Solo, lixo, chorume, pluma de contaminação.

\footnotetext{
${ }^{1}$ Centro de Informações de Recursos Ambientais e de Hidrometeorologia de Santa Catarina (CIRAM), Empresa de Pesquisa Agropecuária e Extensão Rural de Santa Catarina (EPAGRI), Rodovia Admar Gonzaga, 1.347, Itacorubi, 88034-901, Caixa Postal 502, Florianópolis, SC, Brasil. Tel.: (48) 3239-8079; Fax: (48) 3334-1204 -E-mail: andrezalaureano@epagri.sc.gov.br

2 Instituto de Física, Universidade Federal de Mato Grosso (UFMT), Avenida Fernando Correa da Costa, s/n, Boa Esperança, 78060-900 Cuiabá, MT, Brasil. Tel.: (65) 3615-8745; Fax: (65) 3615-8737 -E-mail: shozo@cpd.ufmt.br
} 


\section{INTRODUÇ̃̃̃O}

Nos últimos anos a geofísica aplicada tem sido muito utilizada em estudos ambientais. Vários estudos têm sido realizados em áreas de deposiçãa de resíduos sólidos, onde há suspeita de contaminação provocada pelo líquido que percola do lixo, o chorume.

Vários relatos apresentados em Reynolds (1997) apontam os métodos elétricos e eletromagnéticos como os principais para mapear plumas de contaminação. Considerando-se a rapidez e o baixo custo com que são obtidas as informações, optou-se, no presente trabalho, utilizar o método eletromagnético indutivo e 0 GPR - Radar de Penetração no Solo.

Parte do atual aterro sanitário de Cuiabá e as lagoas de tratamento de chorume não possuem impermeabilização de base, de modo que é possível que haja a formação de uma pluma de contaminação no subsolo. Portanto o objetivo deste trabalho foi verificar a existência dessa pluma, visando determinar a extensão e a profundidade da mesma. A área estudada localiza-se a nordeste da área urbana de Cuiabá, Mato Grosso, Brasil, latitude $15^{\circ} 35^{\prime} 12^{\prime \prime}$ S e longitude $56^{\circ} 04^{\prime} 16^{\prime \prime} \mathrm{W}$, fazendo parte da bacia do rio Cuiabá

\section{CARACTERIZAC̣̃̃O GEOLÓGICA E HIDROGEOLÓGICA}

A área estudada se situa nos domínios geológicos do Grupo Cuiabá, pertencente a Faixa Interna de Dobramentos Paraguai, mais precisamente no compartimento geomorfológico denominado "Baixada Cuiabana". Segundo a proposta de Luz et al. (1980), que subdivide o Grupo Cuiabá na região da Baixada Cuiabana em 9 Subunidades, a região do aterro sanitário de Cuiabá está inserida na Subunidade 5 em contato com a Subunidade 6 , conforme Figura 1.

0 lado noroeste do aterro situa-se dentro da Subunidade 6, constituída por filitos cobertos por camadas de cascalhos de quartzo e laterita, podendo apresentar fraturas preenchidas por quartzo em alguns pontos. A espessura das camadas de cascaIho sobre o filito varia de alguns centímetros a alguns metros. De maneira geral, portanto, sendo o filito a rocha de base, esse lado do aterro é pouco permeável. 0 lado sudeste faz parte da Subunidade 5 , constituída de metarenitos, apresentando grande concentração de fraturas preenchidas por quartzo. Portanto este lado é mais permeável e suscetível à contaminação. 0 nível do lençol freático oscila em torno de $16 \mathrm{~m}$ de profundidade.

\section{METODOLOGIA}

Para 0 levantamento eletromagnético indutivo, foi utilizada a técnica de dupla de bobinas de fonte móvel: uma bobina transmissora Tx e outra receptora Rx, conectadas por um cabo de referência. Junto a Tx há um módulo de controle que produz uma corrente elétrica alternada na bobina. Junto a Rx há um módulo de leitura, onde são efetuadas as leituras de condutividade. A separação entre as bobinas é mantida fixa e o par de bobinas é movido ao longo de uma linha que se deseja estudar, efetuando as medições em intervalos discretos. A bobina TX gera um campo magnético primário Hp, ortogonal à disposição da bobina. Hp induz correntes elétricas no subsolo. No subsolo condutor, essas correntes dão origem a um campo magnético secundário Hs, que é lido por Rx, juntamente com $\mathrm{Hp}$. A razão entre Hs e Hp é proporcional a condutividade aparente (McNeill, 1980). 0 equipamento utilizado foi 0 EM-34, da Geonics. As profundidades teóricas de investigação variaram de 7,5 a $60 \mathrm{~m}$. Foram investigadas 25 linhas, procurando abranger 0 entorno do aterro, conforme a Figura 2. Como se pretendia investigar a condutividade elétrica do subsolo (sem a influência do lixo), não foram realizados ensaios sobre as células de disposição de lixo. Ou seja, procurou-se não medir a condutividade do lixo, que certamente seria elevada, mascarando a real condutividade do subsolo. Os dados dos ensaios eletromagnéticos foram processados utilizando o método de interpolação por krigagem ordinária (Golden Software, 2002) gerando pseudo-seções e mapas de isovalores de condutividade elétrica aparente.

Com 0 GPR foram investigadas apenas as linhas 2 e 9, que são fundamentais para as conclusões deste trabalho. 0 equipamento utilizado foi o Ramac/GPR da Mala GeoScience. 0 mesmo não possui blindagem e, portanto, pode mostrar no perfil as ondas aéreas. A linha 2 situa-se entre as lagoas de tratamento de chorume sem impermeabilização e fica na Subunidade 6 da geologia local. A linha 9 fica na Subunidade 5, que é a mais crítica, pois é bastante permeável (devido ao metarenito) e possui fraturas preenchidas por quartzo. Foi utilizada a antena de $50 \mathrm{MHz}$. A técnica de aquisição foi caminhamento com afastamento constante, com passo de 1,0 m, e empilhamento de 128 sinais. Para a conversão tempo-profundidade se buscou na literatura (Porsani, 1999) os valores de velocidade para os tipos de solos e rochas da área. Considerando-se a litologia da Subunidade 6 (lado norte), descrita anteriormente, adotou-se uma velocidade média de $0,10 \mathrm{~m} / \mathrm{ns}$ para essa região (linha 2). Considerandose a litologia da Subunidade 5 (lado sul), descrita anteriormente, adotou-se uma velocidade média de $0,09 \mathrm{~m} / \mathrm{ns}$ para essa região 


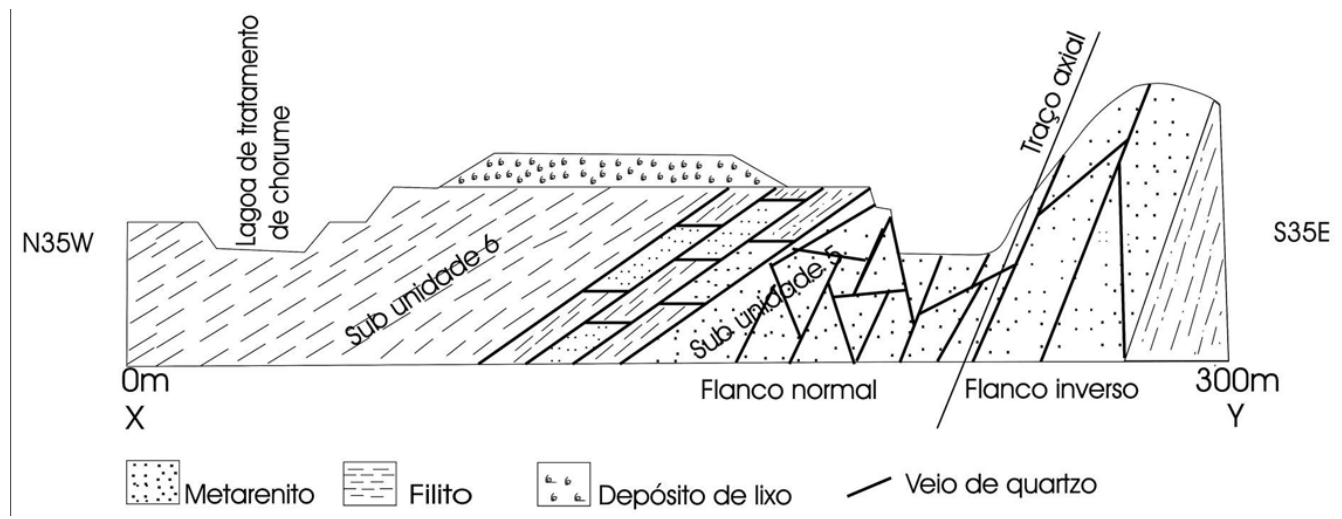

Figura 1 - Perfil geológico transversal do aterro sanitário de Cuiabá (Fernandes et al., 2006).

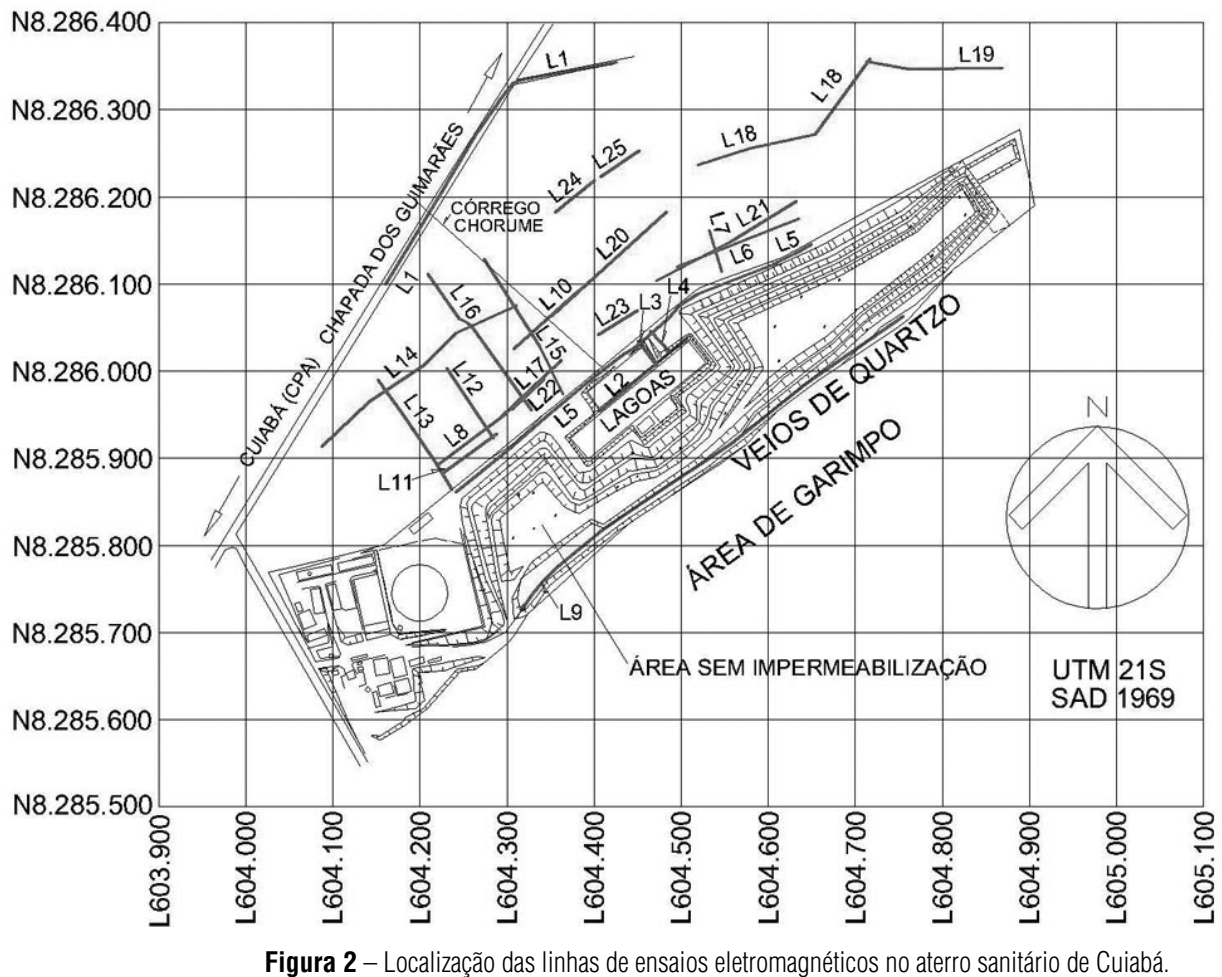

(linha 9). Realizaram-se duas CMPs (Common Mid Point) no local, mas os resultados não foram satisfatórios e, portanto, não puderam ser utilizados.

\section{RESULTADOS}

A condutividade elétrica aparente nas regiões sem contaminação oscilou entre 4 e $16 \mathrm{mS} / \mathrm{m}$, predominando $12 \mathrm{mS} / \mathrm{m}$, que foi considerada a condutividade de background da área. A Tabela 1 apresenta as faixas de condutividade e suas respectivas classificações em relação à contaminação.
Tabela 1 - Classificação para as áreas, adotada para faixas de condutividade elétrica aparente (extraído de Fachin et al., 2006).

\begin{tabular}{|c|c|}
\hline Classificação & $\begin{array}{c}\text { Faixa de condutividade } \\
\text { elétrica aparente }\left(\rho_{a}\right)-\mathrm{mS} / \mathrm{m}\end{array}$ \\
\hline Área não contaminada & $<20$ \\
\hline Área suspeita de contaminação & $20-40$ \\
\hline Área potencialmente contaminada & $>40$ \\
\hline
\end{tabular}

Fachin et al. (2006) estudaram uma área de disposição de resíduos de curtume em Várzea Grande - MT, também na Bai- 

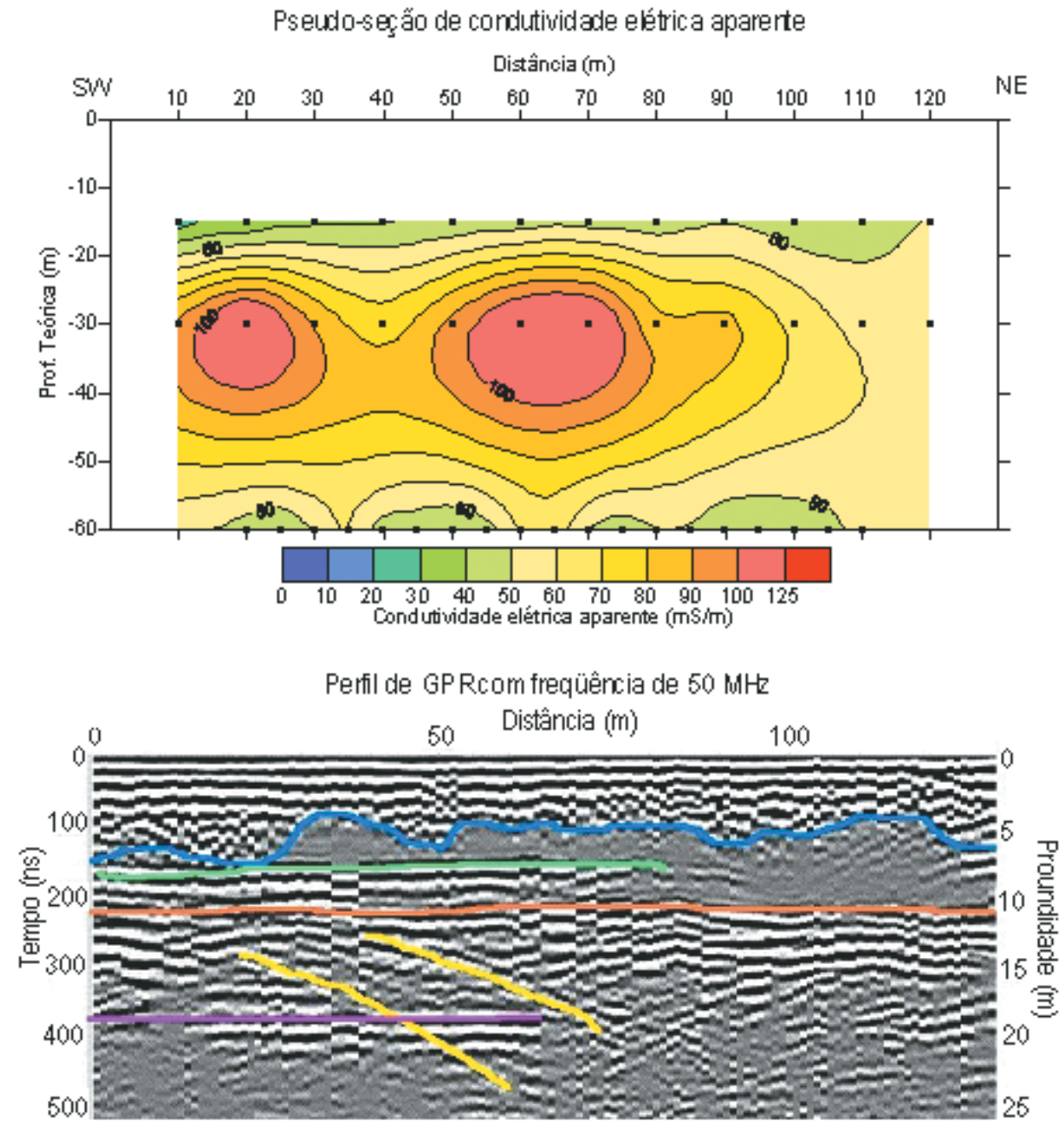

Figura 3 - Resultados da linha 2: a) Pseudo-seção de condutividade elétrica aparente obtida com condutivímetro EM-34; com espaçamento entre as bobinas 10, 20 e $40 \mathrm{~m}$ b) Perfil de GPR adquirido com antenas não blindadas de $50 \mathrm{MHz}$.

xada Cuiabana, e criaram esta classificação para a condutividade elétrica aparente que é adotada nas interpretações deste trabalho.

Existe uma correlação entre os valores elevados de condutividade e uma provável contaminação por chorume proveniente do lixo, uma vez que a condução elétrica ocorre principalmente através de íons, que são abundantes no chorume.

Medidas de condutividade elétrica foram efetuadas em área contígua ao aterro, livre de resíduos e de fontes contaminantes, em períodos distintos, e os valores nunca superaram $10 \mathrm{mS} / \mathrm{m}$. Nesta área foram realizadas as calibrações antes de cala levantamento.

Nas Figuras 3 e 5 são apresentadas as pseudo-seções de condutividade elétrica aparente juntamente com os perfis de GPR das linhas 2 e 9 , respectivamente.
Conforme pode ser observado na Figura 3, os valores de condutividade elétrica foram extremamente elevados, maiores que $40 \mathrm{mS} / \mathrm{m}$, chegando a ultrapassar $100 \mathrm{mS} / \mathrm{m}$ a $30 \mathrm{~m}$ de profundidade. Pode-se correlacionar a condutividade com uma possível contaminação por chorume, uma vez que a condução elétrica ocorre principalmente através de íons, que são abundantes no chorume. Houve valores elevados de condutividade em profundidades de até $60 \mathrm{~m}$. Nas áreas próximas das posições 20 e $65 \mathrm{~m}$ da pseudo-seção, houve um aumento significativo da condutividade aparente, na profundidade em torno de $35 \mathrm{~m}$, que podem indicar regiões mais permeáveis.

0 perfil de GPR da linha 2, apresentado na Figura 3, mostrou ausência de reflexão (abaixo da linha azul), denominada de zona de sombra ou shadow zone, de 25 a $150 \mathrm{~m}$. Esta zona inicia a 


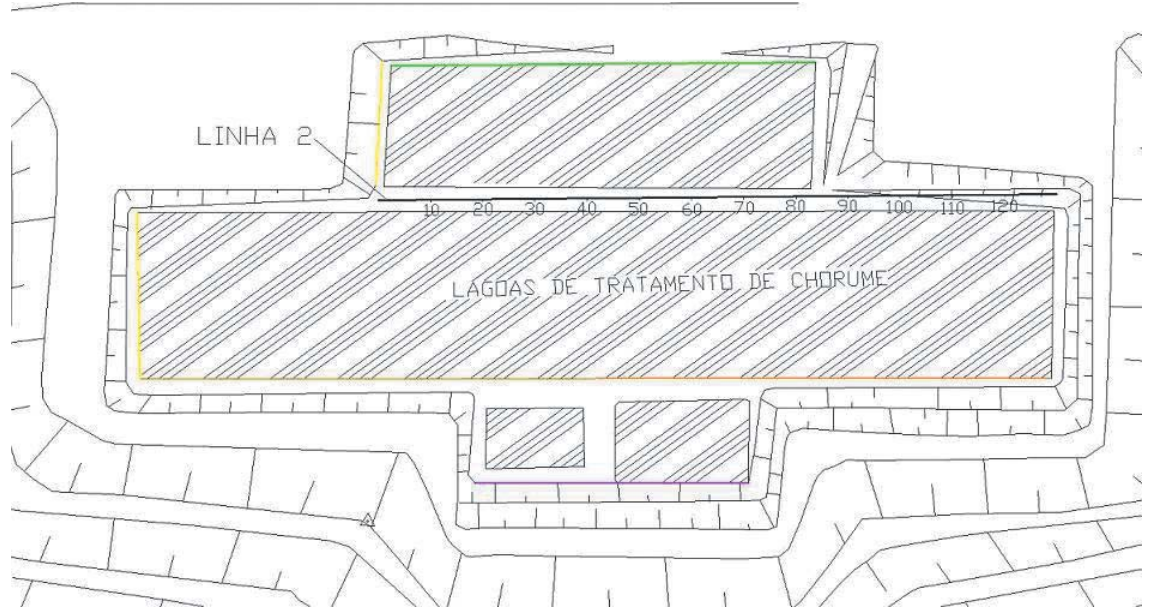

Figura 4 - Localização da linha 2 e dos refletores aéreos interpretados no perfil GPR da Figura 3, assinalados por linhas com as mesmas cores.

5-6 $\mathrm{m}$ de profundidade, logo abaixo do fundo das lagoas e corresponde a atenuação da amplitude do sinal provocada pela alta condutividade do meio. Provavelmente a causa é a ausência de impermeabilização da lagoa que esta possibilitando a percolação de chorume para o substrato da lagoa. Ainda na Figura 3, os refletores assinalados em verde, laranja, rosa e amarelo na seção GRP, foram interpretados como reflexões aéreas provenientes das paredes das lagoas e pelos taludes do aterro, cujas posições podem ser observadas na Figura 4. Esta interpretação baseouse no cálculo da distância dos refletores em relação ao perfil, considerando a velocidade da onda aérea e o tempo de chegada da onda.

Observando-se a pseudo-seção de condutividade elétrica aparente da linha 9 (Fig. 5) nota-se que praticamente todo o perfil apresenta valores de condutividade superiores a $40 \mathrm{mS} / \mathrm{m} \mathrm{e}$, em alguns trechos, ultrapassando $100 \mathrm{mS} / \mathrm{m}$, valores que sugerem a contaminação por chorume.

0 perfil de GPR da linha 9 é apresentado em três segmentos para melhor clareza na Figura 5. 0 perfil mostra ausência de reflexão abaixo da linha azul, indicando regiões de alta condutividade. Estas zonas de sombra estão na maior parte do perfil, abaixo de $14 \mathrm{~m}$ de profundidade. 0 trecho inicial da linha 9 , que é caracterizado por apresentar fraturas aparentes preenchidas por veios de quartzo, apresentou contaminação visível no lago formado ao lado do barranco, que acompanha a linha 9. A situação, portanto, é preocupante, devido à facilidade de percolação do chorume através dessas fraturas. As linhas assinaladas em verde, na Figura 5, foram interpretadas como refletores que podem representar as camadas geológicas e/ou o lençol freático. Considerando o tempo duplo e a velocidade da onda no ar, as linhas amarelas foram interpretadas como ondas aéreas, representando refletores localizados de 45 a $60 \mathrm{~m}$ de distância onde se encontra um paredão que acompanha a linha 9 , nesta distância.

$\mathrm{Na}$ Figura 6 são apresentados os mapas de isovalores de condutividade elétrica aparente para as profundidades teóricas de 15 , 30 e $60 \mathrm{~m}$, respectivamente.

Para a profundidade teórica de $15 \mathrm{~m}$ a zona mais condutiva foi encontrada na região das lagoas e nos lados sul e norte da célula impermeabilizada, principalmente no norte, com valores de condutividade superiores a $40 \mathrm{mS} / \mathrm{m}$. Na época do ensaio o lixo estava sendo depositado nesta parte do aterro, e portanto era mais instável e a produção de chorume certamente era maior. Este chorume produzido provavelmente encontrou pontos de fuga, contaminando o subsolo nessas regiões. Ainda para a profundidade de $15 \mathrm{~m}$, a parte não impermeabilizada apresentou valores de condutividade entre 20 e $40 \mathrm{mS} / \mathrm{m}$, indicando haver contaminação. Provavelmente esses valores foram menores devido à maior estabilidade do lixo, que foi depositado neste local há mais tempo e assim produzindo menos chorume.

Os valores da condutividade aparente para a profundidade teórica de $30 \mathrm{~m}$ aumentaram, ultrapassando os $100 \mathrm{mS} / \mathrm{m}$ nas lagoas e nas áreas com e sem impermeabilização. E, ainda, na maior parte da área do aterro a condutividade foi maior que $40 \mathrm{mS} / \mathrm{m}$, indicando que a contaminação pode ter atingido praticamente todo 0 subsolo imediatamente próximo ao aterro. Na camada de 15 a $30 \mathrm{~m}$ a condutividade aumentou com a profundidade.

De acordo com Caporossi (2002) o nível d'água na área do aterro, em 2001, era de aproximadamente $16 \mathrm{~m}$. Presumindo-se que durante os ensaios o nível d'água manteve-se nesta média, 

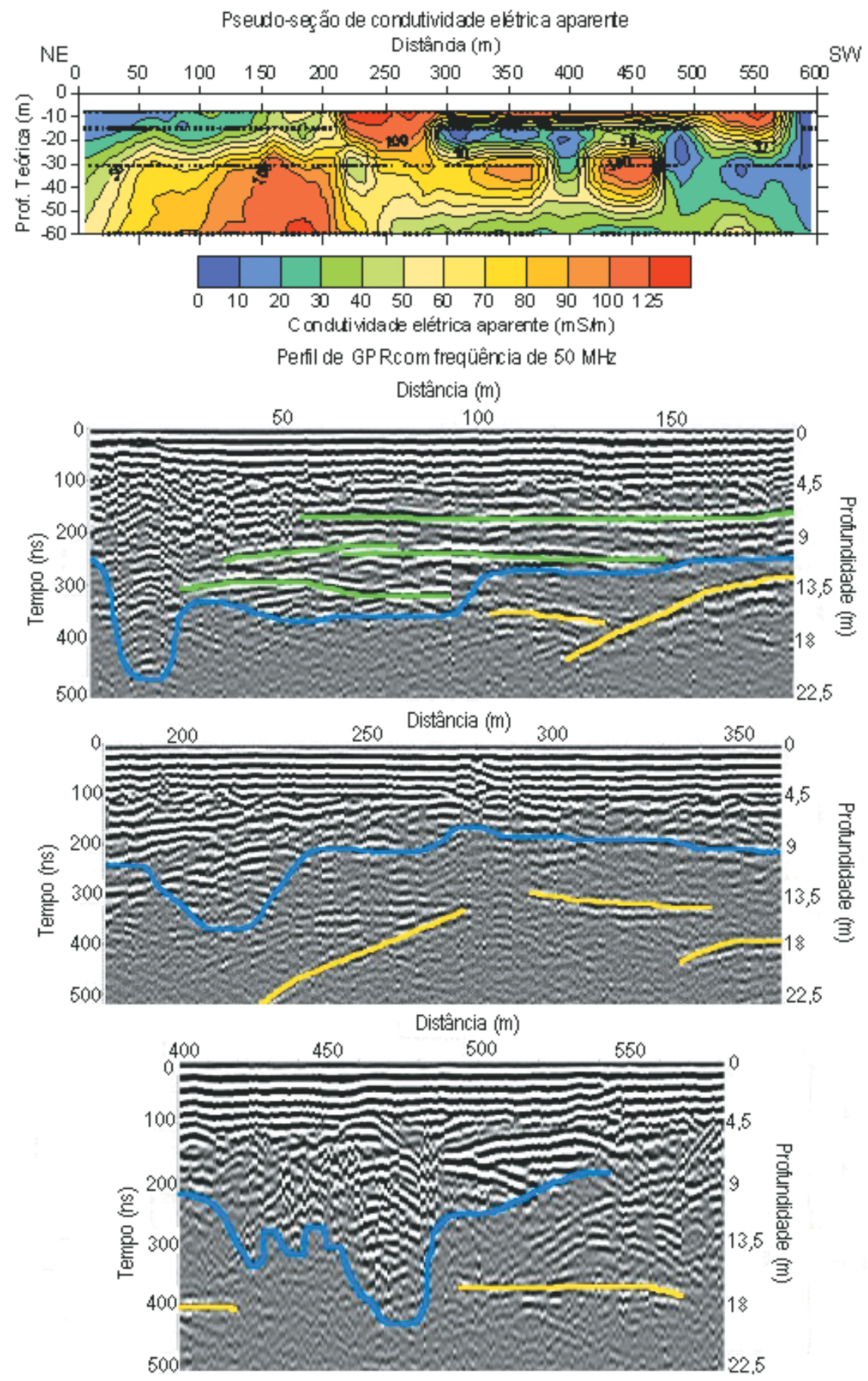

Figura 5 - Interpretação geofísica integrada da linha 9. Acima a pseudo-seção de condutividade elétrica e a seguir o perfil de GPR dividido em três segmentos.

pode-se inferir que 0 aumento da condutividade com a profundidade foi, em parte, reflexo da saturação de água abaixo de $16 \mathrm{~m}$, mas também deve ter havido a influência de contaminantes por causa dos altos valores de condutividade.
Para a profundidade teórica de $60 \mathrm{~m}$ os valores de condutividade foram menores do que para $30 \mathrm{~m}$, principalmente na região das lagoas. Isto indica que, de $30 \mathrm{a} 60 \mathrm{~m}$ de profundidade, a contaminação diminuiu, mas ainda é significativa. 


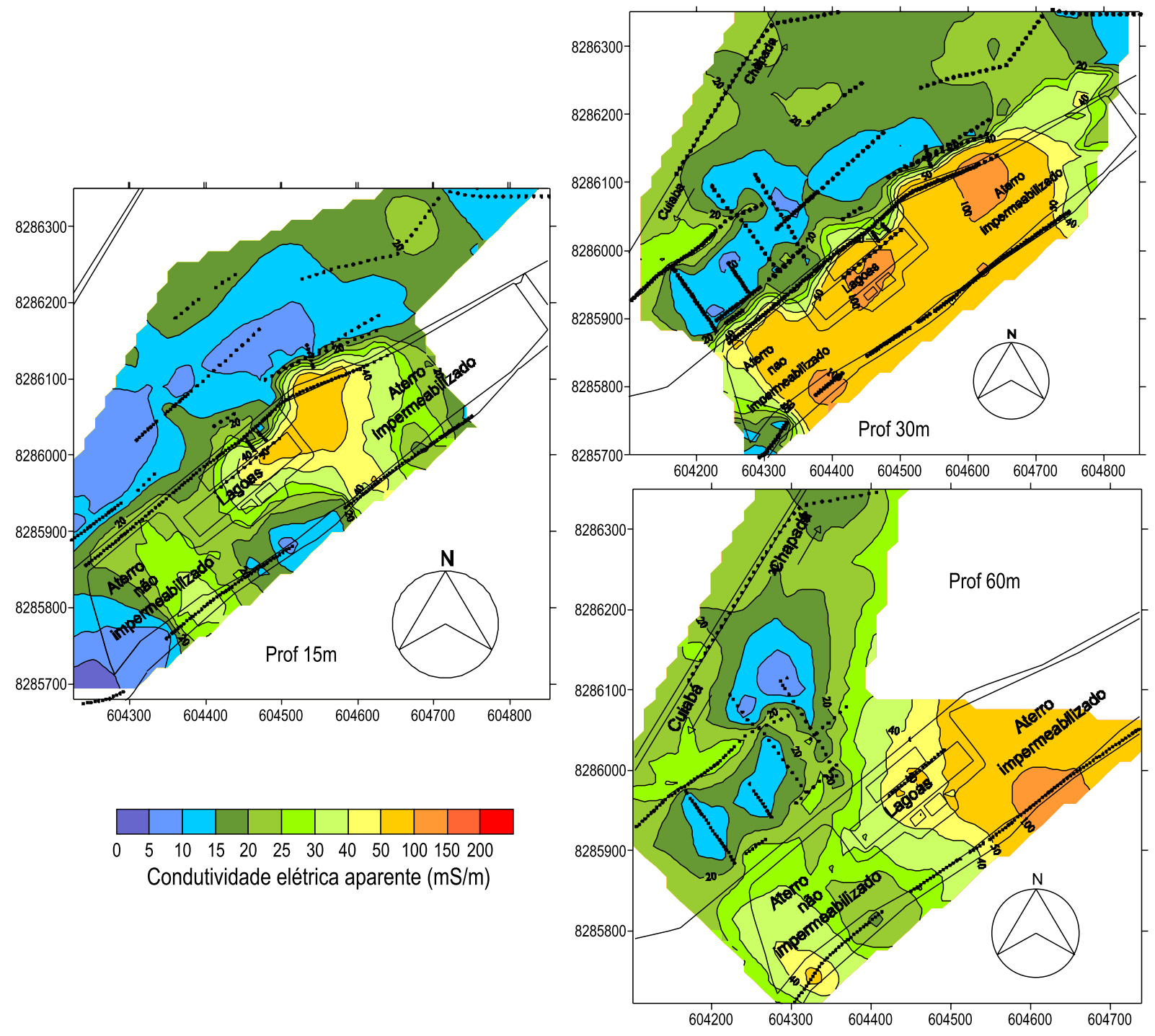

Figura 6 - Mapas de isovalores de condutividade elétrica aparente.

Os resultados indicam que na parte sem impermeabilização pode ter ocorrido contaminação do subsolo, como se poderia esperar. Porém surpreendentemente a condutividade encontrada nessa parte foi menor do que a encontrada na parte impermeabilizada. Supõe-se que isto se deve à maior estabilidade do lixo, que era mais antigo na área sem impermeabilização. Outra possibilidade é a diferença na permeabilidade e na porosidade das rochas nas duas áreas.

\section{CONCLUSÕES}

A vantagem de se usar dois ou mais métodos geofísicos para investigações de contaminação é que os resultados se tornam mais consistentes. 0 GPR dá uma noção mais exata de qual pro- fundidade inicia a contaminação, enquanto o método eletromagnético indutivo mostra a variação de intensidade da contaminação ao longo do perfil e também em mapas de isovalores em diversas profundidades.

Os resultados apontaram anomalia de condutividade, possivelmente relacionada à contaminação do subsolo, em boa parte da área do aterro, sendo mais intensa na região das lagoas de tratamento de chorume e nas laterais sul e norte da célula de aterro impermeabilizado. Obteve-se resultados elevados de condutividade em profundidades teóricas de até $60 \mathrm{~m}$, mas a zona que apresentou as maiores condutividades está na faixa dos $30 \mathrm{~m}$ de profundidade.

Nos locais onde a deposição de lixo era mais recente, mesmo 
havendo impermeabilização de base, os valores de condutividade foram mais elevados, podendo ter havido contaminação do subsolo. Ou seja, a impermeabilização pode não ter sido efetiva, permitindo a fuga de chorume através da base do aterro.

0 aterro sobre a Subunidade 5 constitui-se na área mais problemática, pois há presença de metarenito, que possui maior permeabilidade, porosidade, além das fraturas preenchidas por quartzo, oferecendo riscos aos recursos hídricos subterrâneos. Os resultados sugerem que nessa área houve uma provável contaminação. No lado norte, onde não há resíduos depositados, predomina a Subunidade 6, composta basicamente por filitos, e filitos conglomeráticos, os valores de condutividade ficaram abaixo de $20 \mathrm{mS} / \mathrm{m}$.

Em vista dos resultados obtidos, recomenda-se que seja realizada uma investigação que comprove a contaminação.

\section{REFERÊNCIAS}

CAPOROSSI SSA. 2002. Análise Comportamental do Chorume do Aterro Sanitário e do Sistema de Tratamento na Central de Disposição Final de Resíduos Sólidos Urbanos de Cuiabá/MT. Dissertação (Mestrado em Ciências em Engenharia Civil) - Coordenação dos Programas de PósGraduação de Engenharia, Universidade Federal do Rio de Janeiro, Rio de Janeiro. 109 p.
FACHIN SJS, HUBER F, SHIRAIWA S, BORGES WR \& MIGLIORINI RB. 2006. Aplicação de métodos geofísicos para identificar áreas contaminadas por resíduos de um curtume. Rev. Bras. Geof., 24(1): 129-138.

FERNANDES MC, GARCIA FO \& CATEN BT. 2006. Relatório do campo de geofísica no aterro sanitário de Cuiabá. Cuiabá. Relatório interno. ICET/UFMT. $6 \mathrm{p}$.

GOLDEN SOFTWARE. 2002. SURFER version 8. Surface Mapping System Copyright ${ }^{(}$, Colorado.

LUZ JS, OLIVEIRA AM, SOUZA JO, MOTTA JFM, TANNO LC, CARMO LS \& SOUZA NB. 1980. Projeto Coxipó - Relatório Final. Goiânia, DNPM/CPRM, v. 1. $136 \mathrm{p}$.

McNEILL JD. 1980. Electromagnetic terrain conductivity measurement at low induction numbers. Tech. Note TN-6, Geonics Ltd., Mississauga, Ontario, Canada, $13 \mathrm{p}$.

PORSANI JL. 1999. Ground Penetrating Radar (GPR): Proposta metodológica de emprego em estudos geológico-geotécnicos nas regiões de Rio Claro e Descalvado, SP. Tese (Doutorado em Geociências), Instituto de Geociências e Ciências Exatas, Universidade Estadual Paulista, Rio Claro. 159 p.

REYNOLDS JM. 1997. An introduction to applied and environmental geophysics. John Wiley \& Sons, Chichester. 795 p.

\section{NOTAS SOBRE OS AUTORES}

Andreza Thiesen Laureano é engenheira sanitarista e ambiental pelo Departamento de Engenharia Sanitária e Ambiental do Centro Tecnológico da Universidade Federal de Santa Catarina (ENS/CTC/UFSC) em 2004. Mestre (2007) pelo Programa de Pós-Graduação em Física e Meio Ambiente do Instituto de Ciências Exatas e da Terra da Universidade Federal de Mato Grosso (PPGFMA/ICET/UFMT). Atualmente é pesquisadora da Empresa de Pesquisa Agropecuária e Extensão Rural de Santa Catarina (EPAGRI), na área de recursos hídricos.

Shozo Shiraiwa é Doutor em Geofísica pela Universidade de São Paulo (1994) e Professor Associado da Universidade Federal de Mato Grosso. Leciona e orienta nos cursos de Mestrado em Física Ambiental e Recursos Hídricos, de Graduação em Geologia, Física e Engenharias, desenvolvendo pesquisas na área de geofísica aplicada, com os métodos: radar de penetração no solo, eletromagnético indutivo, magnetométrico, gravimétrico e eletrorresistivo. 